\title{
Inclusion of marginalised groups in sensitive programming in Pakistan
}

Roz Price

Institute of Development Studies

14 April 2021

\section{Question}

- What is the evidence on what works with respect to the inclusion of marginalised groups (children, women and girls, persons with disabilities, transgender, and religious minorities) in interventions designed to work on sensitive issues such as gender-based violence, child and forced marriages, and/or freedom of religion?

\section{Contents}

1. Summary

2. General lessons learned

3. Project examples and lessons from Pakistan

4. Other country lessons

5. References

The K4D helpdesk service provides brief summaries of current research, evidence, and lessons learned. Helpdesk reports are not rigorous or systematic reviews; they are intended to provide an introduction to the most important evidence related to a research question. They draw on a rapid deskbased review of published literature and consultation with subject specialists.

Helpdesk reports are commissioned by the UK Foreign, Commonwealth, and Development Office and other Government departments, but the views and opinions expressed do not necessarily reflect those of FCDO, the UK Government, K4D or any other contributing organisation. For further information, please contact helpdesk@k4d.info. 


\section{Summary}

Pakistan continues to experience high levels of discrimination against marginalised groups including women and girls, people with disabilities and religious minorities. These groups are more vulnerable to violence, abuse, exploitation, exclusion, poverty etc. Furthermore, many of them face intersecting and overlapping inequalities (due to their gender, caste, sex, race, class, sexuality, religion, (dis)ability etc). This rapid review explores lessons learned in how these marginalised groups have been included in interventions aimed at addressing sensitive issues in Pakistan (such as gender based violence, forced marriages and freedom of religion). Despite the recognition of the importance to "leave no one behind" in the sustainable development goals, marginalised communities are the very people on whom there is the least data, and rigorous, explicit evidence of how to leave no one behind in practice in Pakistan remains limited. There are a number of general toolkits, guides and summaries that have been produced aimed at including marginalised populations in development and humanitarian programming, however, these tend to focus on best practice in the general design of interventions. Lessons learned on what works (in Pakistan) for the inclusion of marginalised groups in sensitive programming more specifically were lacking. Importantly, the complexity of intersectionality and the differentiation in experiences within and across different marginalised groups on the ground need to be recognised and acknowledged (Tadros, 2020b). Hence nuanced approaches with contextual understanding is key and generalisations across all these groups should be taken cautiously with this in mind. The majority of the literature identified in this review comes from policy and non-governmental organisation (NGO) sources.

Given the time constraints in writing of this rapid review, it does not discuss the experiences and history of marginalised groups in Pakistan or explore the extent of relevant programming and donors working on sensitive topics in Pakistan. In section 2, the review briefly touches on some general lessons on VAWG programming and the inclusion of marginalised groups. In section 3, project examples and lessons from sensitive programming in Pakistan are explored. Finally, section 4 gives some lessons learned from sensitive programming in other Asian countries (Indonesia and India). In general there appears to be more evidence around the inclusion of women and girls (and children) in gender-based violence prevention interventions - especially from the 6-year UK Aid funded What Works to Prevent Violence Against Women and Girls Global Programme. Less information was found on freedom of religion programming in Pakistan, but this issue is gaining more attention, e.g. through the UK Aid funded Coalition for Religious Equality and Inclusive Development (CREID). Despite the recognition of the high vulnerability often faced by people with disabilities (especially women) to violence, exclusion and discrimination, few of the programmes or literature identified in this rapid review explicitly discussed the inclusion or targeting of people with disabilities in Pakistan. There was also little information found on including lesbian, gay, bisexual, transgender, queer or questioning and intersex plus (LGBTQI+) persons in programming in Pakistan.

Taking learnings from previous programmes in Pakistan (including the What Works to Prevent Violence Against Women and Girls Programme; CREID programme; three inter-linked Oxfam initiatives in Pakistan - Raising Her Voice (RHV), Transformation of Elected Nominees (LISTEN) and She Can Lead (SCL); the AAWAZ and CDIP programmes; and the Empowerment, Voice and Accountability for Better Health and Nutrition (EVA-BHN) project), key commonalities and themes that emerge around including marginalised groups in (sensitive) programming include: 
- Important for constant engagement, understanding and trust building with marginalised communities, who have often experienced traumas and live in constant fear of persecution. Creating culturally sensitive and safe spaces is key. E.g. see the three women's empowerment initiatives by Oxfam (Khattak \& Higdon, 2020).

- Undertake community engagement, especially using community gatekeepers or local 'experts' with experiences of cultural norms, context and inequalities and who are trusted by the community. E.g. research undertaken for CREID into religious minority experiences of intersecting inequalities in Pakistan used lead researchers from the same communities (such as Hindu, Christian) to engender trust, connect with the participants and explain the research in a way participants could understand (Sultan et al., 2020; Maheshwary, 2020; Suleman, 2020). The women's empowerment initiatives in Pakistan by Oxfam emphasise the key role that harnessing the support of local women leaders to support marginalised women played in project success (Khattak \& Higdon, 2020).

- Use methodological innovation (e.g. participatory and collaborative approaches at the grass roots level over traditional professionally led interventions such as structured interviews) - this is particularly important for working with marginalised groups. In India, Bharadwaj, Howard and Narayanan (2021) used participatory action research (PAR) methodologies to generate data with marginalised communities, ensuring that they are given a voice to share and analyse their experiences.

- Use and build upon existing networks, structures, and NGOs. E.g. the first stage of AAWAZ built upon the experience, credibility, networks, and social capital of leading development NGOs in Pakistan (Khan \& Qidwai, 2021). The Oxfam initiatives engaged with and involved a range of strategic allies at local, national, and international levels (Khattak \& Higdon, 2020).

- Use peace mapping, power analysis, political economy analysis etc to understand the context and bring communities together. E.g. AAWAZ forums used peace mapping and power analysis exercises to help identify conflict triggers and pre-emption strategies, and these exercises brought communities together to work as active agents (Khan \& Qidwai, 2021).

- Engage with male family and household members. AAWAZ worked with male family and household members of the mobilised women to sensitise both about the rights of women (Khan \& Qidwai, 2021). This is one of What Works global programme's ten core elements that seem to have influenced success across diverse VAWG interventions (Jewkes et al., 2020).

- Thickening, and working in multiple entry points and sites rather than conventional scaling up. E.g. the EVA-BHN project prioritised building its presence within the localities it worked, taking the time to understand its context, rather than scale up. CREID recommends pursuing multiple entry points and working in multiple sites within and across countries when promoting freedom of religion and beliefs (FoRB) in fragile contexts (Tadros, 2020a).

- Work synergistically with and build on other programmes; relationship building takes time. AAWAZ and CDIP were designed to work in synergy with significant overlap in their goals (Khan \& Qidwai, 2021). Oxfam has had three initiatives in Pakistan around women's political participation and empowerment over the last decade that have built on one another (Khattak \& Higdon, 2020). 


\section{General lessons learned}

\section{Guidance for including marginalised groups}

A number of general guides and summaries have been produced over the years for including vulnerable and marginalised groups in development programming. For example, UNDP created a Guide and Toolkit in 2010 on including marginalised minorities in developing programming, to help its staff and others to better "understand the conceptual issues and fundamental principles relating to the promotion and protection of minorities, learn how to draw on the available international and regional standards to engage minorities in development programming processes, influence policy choices, as well as increase their opportunities for meaningful participation and representation in development processes" (UNDP, 2010, p. xiii). Part III in the toolkit provides "nine tools to assist UNDP staff in building and/or strengthening their work on minorities in development". A K4D Emerging Issues Report from 2018 on Scaling up inclusive approaches for marginalised and vulnerable people by Carter et al., looks at how to design scalable inclusive change interventions, with a focus on interventions aiming to deliver inclusive outcomes for women and girls (with a particular focus on preventing violence against women and girls) and persons with disabilities.

\section{Violence against women and girls (VAWG) programming}

The What Works to Prevent Violence Against Women and Girls Programme ${ }^{1}$ was a flagship DFID programme investing £25 million over six years (2013-2019) to the prevention of violence against women and girls (VAWG) across Africa, Asia and the Middle East (including an intervention in Pakistan). The programme gathered evidence on what works in preventing VAWG interventions, evaluating 15 interventions designed to reduce VAWG, with an emphasis on addressing physical and sexual violence by intimate partners, violence in the family, and bullying and violence in schools (Jewkes et al., 2020a, p. 2).

In an evidence report and brief summarising the findings of the What Works global programme, Jewkes et al. (2020a, p. 6; 2020b, pp. 33-34) highlight ten core elements that seem to have influenced success across the diverse interventions:

- Rigorously planned, with a robust theory of change, rooted in knowledge of local context (i.e. context- and population-appropriate).

- Address multiple drivers of VAWG, such as gender inequity, poverty, poor communication, and marital conflict.

- Especially in highly patriarchal contexts, work with women and men, and where relevant, families. They highlight "notable examples, in Bangladesh, India and South Africa, of interventions that did not impact on violence at least in part because male partners were not effectively engaged, or because it was assumed that women and girls alone could fundamentally change gender relationships and prevent violence" (Jewkes et al., 2020b, p. 33). In highly patriarchal contexts characterised by strong extended families

${ }^{1}$ See https://www.whatworks.co.za/ 
into which young women marry, the programme found that family-centred models are potentially effective, especially at building trust and preventing backlash.

- Based on gender and social empowerment theories that view behaviour change as a collective rather than solely individual process and foster positive interpersonal relations and gender equity.

- Use group-based participatory learning methods, for adults and children, that emphasise empowerment, critical reflection, communication and conflict resolution skills building.

- Age-appropriate design for children with a longer time for learning and an engaging pedagogy such as sport and play.

- Carefully designed, user-friendly manuals and materials supporting all intervention components to accomplish their goals.

- Integrated support for survivors of violence (e.g. through direct engagement with women experiencing intimate partner violence or community-based referrals).

- Optimal intensity: duration and frequency of sessions and overall programme length enables time for reflection and experiential learning. Need to provide time for change.

- Staff and volunteers are selected for their gender equitable attitudes and nonviolence behaviour, and are thoroughly trained, supervised, and supported.

In a 2019 PowerPoint presentation summarising key points from the programme, Jewkes (2019, p. 8) notes the role of community change agents for social norms interventions, but that they are not always effective; there is need for being well-trained and supported and a long time frame. Other key elements of more effective social norms interventions include the need for interpersonal engagement addressing drivers of violence, alongside awareness raising. Enabling access to services and counselling couples is also important. Education-related interventions in schools can significantly reduce peer violence and corporal punishment, especially if they are developmentally appropriate. More effective education interventions need to: recognise that children take time to learn; include critical reflection, empowerment to communicate and address gendered power; reach out to families and communities; be delivered by highly trained teachers, NGO staff or coaches (Jewkes, 2019, p. 9).

The evidence report and brief conclude by drawing out three best practices in VAWG prevention that have emerged from the programme (Jewkes et al., 2020a, 2020b):

- Commissioning and planning VAWG prevention programmes: Multiyear funding (at least three years) is required for prevention programming that seeks to change social norms in communities or work with children. Rigorous training of personnel needs to be planned and budgeted for at the start of the project, as well as in-service training and ongoing supervision and support.

- Selection and training of personnel: "Personnel working on VAWG prevention need to be gender equitable and non-violent and so NGOs that have not previously worked on VAWG prevention may need to employ new staff or volunteers for the work" (Jewkes et al., 2020, p. 6). In order to relate to and influence beneficiaries, the authors also recommend that personnel "share characteristics with beneficiaries on age, gender and being from the community, and be respected by them" (Jewkes et al., 2020a, p. 6). 
Training must be well-planned and resourced (e.g. thorough understanding of the whole intervention, facilitation training). Before deployment to the field, staff should be asked to demonstrate that they have the appropriate skills.

- Adapting interventions: Sensitivity to the local context is key - "ideally, intervention adaptation needs to be thoughtful about local drivers and context of violence, culture and local political dynamics, and should be based on formative research to ensure a ready fit between intervention and context" (Jewkes et al., 2020a, p. 6). A sufficiently long inception phase is important (to allow proper intervention adaptation, testing and staff selection and training).

\section{Lack of data and information on the most marginalised populations}

A recent rigorous global evidence review of interventions to prevent violence against women and girls was undertaken by the What Works global programme (Kerr-Wilson et al., 2020). The review found "major gaps in evaluations of interventions for the most marginalised groups of women and girls, who experience disproportionately high rates of violence" (Kerr-Wilson et al., 2020 , p. vi). These groups included adolescent girls out-of-school; conflict-affected populations; women and girls living with disabilities; lesbian, gay, bisexual, transgender, queer or questioning and intersex plus (LGBTQI+) persons. Furthermore, it has been highlighted in the academic literature that development is inherently heteronormative in its narratives, policies, and practices (Lind, 2010).

\section{Project examples and lessons from Pakistan}

\section{Oxfam - Women's empowerment in Pakistan}

Oxfam (funded by UK and Australia) has been working in Pakistan for the past decade on strengthening women's political participation and empowerment ${ }^{2}$ (including preventing VAWG) by working with and supporting local partners and civil society. Khattak and Higdon (2020) as part of Oxfam's Inspiring Better Futures Case Study Series, examine three inter-linked Oxfam initiatives in Pakistan: Raising Her Voice (RHV) (2008-13)3; Leverage in Social Transformation of Elected Nominees (LISTEN) (2013-17) ; $^{\text {S She Can Lead (SCL) (2017-20) }}$. RHV in Pakistan established and trained local Women Leaders Groups (WLGs), which LISTEN and SCL subsequently built on and scaled up. All three initiatives adopted "a non-confrontational

\footnotetext{
2 The Women's Voice and Leadership Program is the most recent iteration, a 5 year programme (2019-2024) supported by Canada and implemented by Oxfam Canada, it works to support women's rights organisations in Pakistan to be better managed and more self-sustaining, using a combination of funding and capacity building. See https://www.oxfam.ca/project/womens-voice-and-leadership-pakistan/
}

\footnotetext{
${ }^{3}$ RHV was a multi-country initiative and focused on empowering poor women marginalised in the social, religious, and economic spheres to increase their participation in public policy, budget setting and decision making by supporting women's leadership (Repila, 2013 cited in Khattak \& Higdon, 2020, p. 3).
}

\footnotetext{
${ }^{4}$ LISTEN "built on RHV to further support the strengthening of women's capacities from a political perspective" (Khattak \& Higdon, 2020, p. 3).
}

${ }^{5} \mathrm{SCL}$ aimed to make "electoral processes more responsive to women, promoting their political participation and leadership in terms both of casting votes and standing for election themselves" (Khattak \& Higdon, 2020, p. 3). 
approach and the principle of do no harm, to prevent women, or their advocates, being exposed to greater levels of violence or having their already narrow political space further restricted by men. In addition, partners and WLGs were trained on child protection and safeguarding" (Khattak \& Higdon, 2020, p. 6).

Key insights on the approach include (Khattak \& Higdon, 2020, pp. 5-6):

- It empowered and harnessed the support of local women leaders to support marginalised women.

- Created a culturally sensitive, safe and enabling environment for men and women from diverse cultural, religious and ethnic backgrounds to discuss and unite and challenge sensitive social norms and behaviours relating to gender roles and domestic violence.

- Won buy-in from powerful and influential local male role models to help champion the rights of women locally.

- Engaged with and involved a range of strategic allies at local, national and international levels.

The case study highlights a number of change strategies that were used to achieve horizontal and vertical scaling in Pakistan (Beardon and Otero, 2013; H\&H Consulting, 2013; Repila, 2013 all cited in Khattak \& Higdon, 2020, pp. 17-19). Those that may be relevant to engaging with marginalised women include (Khattak \& Higdon, 2020, pp. 17-19):

- Challenging norms and strengthening voice: "Throughout the programme, the deeply rooted work around personal transformational change was facilitated with the support of local women leaders living in the communities, rather than by government or NGO staff" (Khattak \& Higdon, 2020, p. 17). Capacity building was provided in the first stage of RHV to women who had already been publicly active in their communities on gender issues/political participation.

- Targeting influential local women: "Instead of directly recruiting marginalized women to join the WLGs, the programme targeted local influential women, often educated, to serve as exemplars of personal transformation to women in the wider community and to demonstrate to them how members of civil society could interact effectively with government" (Khattak \& Higdon, 2020, p. 18).

- Developing networks: "Another key strategy was to bring women out of isolation by establishing networks. The WLGs compiled informal directories of their members' skills and contacts and formal directories of local service providers, political actors and government officials. The multiplier effect of these contacts and this information increased the potential for support and influence, and the concept of safety in numbers reduced the risk of individuals being threatened with violence. Relationships were also developed with local elders and religious scholars" (Khattak \& Higdon, 2020, p. 18).

- Media representation: "RHV Pakistan and subsequent initiatives worked with the media at a national level to develop common messages on key governance issues for translation and broadcast in local languages on local channels. This was complemented by collaboration with local media to raise the profile and promote the achievements of WLG members and other women activists" (Khattak \& Higdon, 2020, p. 18). 


\section{Coalition for Religious Equality and Inclusive Development (CREID) - Pakistan}

The Coalition for Religious Equality and Inclusive Development (CREID) is led by the Institute of Development Studies in partnership with Al-Khoei Foundation, Minority Rights Group and Refcemi (the Coptic Office for Advocacy and Public Policy). CREID "provides research evidence and delivers practical programmes which aim to redress the impact of discrimination on the grounds of religion or belief, tackle poverty and exclusion, and promote people's wellbeing and empowerment." ${ }^{6}$ CREID focuses on producing new research evidence in Egypt, Iraq, Myanmar/Burma, Pakistan and Nigeria. Inclusive community development practices are at the centre of CREID's approach to addressing intersecting inequalities (Tadros, 2020a).

\section{Positionality - benefits of researchers being from the same marginalised communities}

A recent CREID policy briefing (Maheshwary, 2020) explores the experiences of intersecting inequalities for poor Hindu women in Karachi, Pakistan. The research was carried out from March-June 2020, through four focus group discussions (FGDs) with 46 participants (34 women and girls (across three focus groups) and 12 men). A participatory ranking methodology called Pile, Rank and Analyse (PRA) was used in the FGDs, which "enables participants themselves to identify problems and challenges, and rank these in order of their priority" (Maheshwary, 2020, p. 2). Discussion was then facilitated by the researcher. The brief emphasises that the FGDs and ranking process were led by a researcher "who is herself a Hindu woman living in Pakistan and who has experienced similar discrimination and exclusion [- allowing her] to connect well with the participants and explain the research questions in a way that she knew they would understand" (Maheshwary, 2020, p. 2). Two other CREID policy briefs (Sultan et al., 2020 and Sultan et al., 2020) using the same methodology and exploring the experiences of intersecting inequalities for women and girls in other religious minorities (Hazara Shia and Christianity respectively) also emphasise that the lead researchers were also from the same communities as the participants. This allows for trust building and the sharing of similar life experiences and was "essential for empowering research participants to speak candidly about their experiences" (Sultan et al., 2020, p. 2). The importance of being sensitive to positionality (of both the researchers but also participants) in the research of marginalised communities is also discussed by Tadros (2020b, pp. 9-11 - see also next section).

\section{Violence and Discrimination against Women of Religious Minority Backgrounds in Pakistan}

A recent special collection of papers was produced by CREID to highlight the lived experiences of women who belong to religious minorities in Pakistan, which "has been a blind spot both in international development policy engagement and in much of the international scholarship on women, security and peace" (Tadros, 2020b, p. 6). In the introduction, Tadros (2020b, p. 8) succinctly argues that

\footnotetext{
${ }^{6}$ Taken from https://www.ids.ac.uk/programme-and-centre/creid/
} 
A nuanced approach is needed to understand how geographic locality, caste, class, and the doctrinal position of the mainstream religion lead to differentiated realities on the ground. This allows us not to assume that the realities of all women who belong to religious minorities within a given context are shaped by the same dynamics, nor that all women who belong to religious minorities experience the same set of inequalities. The sites of discrimination, both physical and emotional, sometimes means they can be targeted in different ways. This has huge implications on our interpretive frameworks, methodologies, and our mobilisational strategies (Tadros, 2020b, p. 8).

\section{Promotion of freedom of religion and beliefs (FoRB)}

Another briefing by CREID draws on emerging lessons in promoting FoRB in fragile contexts taken from its research. This briefing is aimed at sharing insights that may help external actors with the challenges they face in trying to promote FoRB (such as navigating sensitivities, consistency in promotion in complex environments, or engaging with contending legitimacies of different partners). The three insights emerging from CREID so far may be useful to programming on FoRB trying to reach the most marginalised in Pakistan. They are (Tadros, 2020a, p. 2):

1. Pursue multiple entry points to promote FoRB as part of a broader agenda supporting inclusive politics and society.

2. Work in multiple sites within and across countries. This recognises that the political situation is not always uniform across countries, e.g. in Pakistan, the possibilities of redressing the inequalities facing religious minorities vary dramatically between one site and another and also vary according to levels of poverty, class/caste, geographic location, and profession (Tadros, 2020a, p. 4).

3. Work with multiple partners with different repertoires of power in the community. CREID has "learned to be sensitive to the multivocality of communities which experience intersecting inequalities and to never assume that if they share the same religion, they will share the same denomination or historical experience of marginalisation... Engaging with multiple voices... is key to reflecting the diversity within society itself" (Tadros, 2020a, p. 6).

Rather than scaling up in conventional terms, these learning "points amount to the importance of considering a broader strategy of "a multitude of smalls"' in fragile contexts, which allow FoRB interventions to be more agile (Tadros, 2020a, p. 9).

The CREID programme found that in both Iraq and Pakistan the bringing together of actors (both faith and no-faith) in a safe space was extremely enabling for FoRB promotion as it allowed for cross-country exchanges of experiences and expertise, and the "creation of solidarities between people who would not have conventionally come together within and across countries" (Tadros, 2020a, p. 7).

\section{AAWAZ and CDIP in Pakistan}

Khan and Qidwai (2021) undertook a comparative case study of the Consolidating Democracy in Pakistan (CDIP) and AAWAZ Voice and Accountability programmes in Pakistan. Both programmes helped to nurture active citizenry and promote social cohesion in the face of severe 
constraints on civil society and weak democratic institutions. They both targeted marginalised groups, with AAWAZ seeking to build the capacity, participation and representation of women, youth and excluded groups (such as religious minorities, transgender people, people with disabilities, landless and ethno-linguistic minorities). CDIP aimed to increase the political participation as voters and in political parties of women, people with disabilities, transgender people, and nomads specifically. AAWAZ created an apparatus of participation and representation through a network of forums (village councils, district women's assemblies and provincial forums), youth circles of influence, open courts ('khuli katcheries'), and Aagahi centres. In particular, the Aagahi centres, "conceptualised as women-friendly spaces and staffed by a local woman resource person (RP) in each district, provided training on human rights, domestic violence awareness, conflict pre-emption and peace building" (Khan \& Qidwai, 2021, p. 43). RPs helped to build trust and sensitise locals to gender issues, they "assisted locals in meeting up across religious, gender and class divides, sensitising and training them on political and social issues" (Khan \& Qidwai, 2021, p. 45). All AAWAZ forums had at least 50 per cent female participation.

The different levels of this AAWAZ apparatus were "in effect a means to off-set patronage politics and elite capture at the district level by including representation in AAWAZ forums from previously excluded groups and ensuring that citizen's demands were heard" and these new spaces bypassed significant barriers to empowerment and accountability at the local level (Khan \& Qidwai, 2021, p. 43).

Initially, "CDIP found it difficult to mobilise members of the public for its voter registration campaign, so it did not make avoiding elite capture a priority. If local influentials actively participated they were encouraged to continue, so the programme could establish 'buy in' within the community. Subsequently the programme slowly included marginalised groups, and trained them in avoiding hijacking of the political space by influential elites" (Khan \& Qidwai, 2021, p. 46).

Some other key programme factors included:

- Using peace mapping and power analysis to bring communities together: "AAWAZ forums used peace mapping and power analysis exercises effectively to help identify conflict triggers and pre-emption strategies. A review found the exercises themselves brought communities together, working as active agents to preserve peace (DFID 2016)" (Khan \& Qidwai, 2021, p. 61). Another method was bringing inter-faith communities together before religious holidays to discuss ways to avoid clashes.

- Using and building upon existing networks, structures and NGOs: "The AAWAZ structure built upon the experience, credibility, networks and social capital of leading development NGOs in Pakistan." These organisations, particularly Aurat Foundation, have a history of rights-based advocacy in Pakistan and were able to bring their "extensive experiences of building local networks and a framing of empowerment and accountability to bear on how AAWAZ was designed and implemented" (Khan \& Qidwai, 2021, p. 61).

- Engaging with local 'experts' with experiences of cultural norms, context and inequalities: In AAWAZ these locals reported not experiencing high levels of resistance from communities, but did so from the institutions (Khan \& Qidwai, 2021, p. 62).

- Engaging with male family and household members: The AAWAZ consortium partners and women in the communities "report the biggest barriers to mobilising women were patriarchal cultural norms, and resistance from local influential and religious scholars." So 
"AAWAZ worked with the male family and household members of the mobilised women, to sensitize both about the rights of women" (Khan \& Qidwai, 2021, p. 62).

- Working together and synergistically with other programmes: AAWAZ and CDIP "were designed to work in synergy with significant overlap in their goals. Their interaction effects emerged clearly at multiple levels" (Khan \& Qidwai, 2021, p. 64). They (fortuitously and strategically) shared an implementing partner (DAl) and were based on political economy analysis (PEA) and CAR (Context, Action, Result) analysis. "The interaction effect of the two programmes strengthened women's capacity to counter patriarchal and elite capture of democratic processes at the local level by providing them opportunities to engage with elected officials and participate in voting" (Khan \& Qidwai, 2021, p. 63).

\section{Reaching the most marginalised through community participation}

The Empowerment, Voice and Accountability for Better Health and Nutrition (EVA-BHN) project in Pakistan was implemented by Palladium in partnership with the Centre for Communications Programmes Pakistan (leading on work with media and religious leaders) (Palladium, 2016, p. 3). The project aimed to "empower, organise and facilitate Pakistan's citizens to hold the provincial governments of Punjab and Khyber Pakhtunkhwa (KP) to account for the delivery of quality reproductive, maternal, new-born, child health and nutrition services (RMNCH-N)" (Kirk, 2017, p. $3)$. It sought "to include the poor and marginalised, including women, religious minorities and lower castes, in its activities" (Kirk, 2017, p. 15). However, a series of entrenched attitudes sometimes made this difficult, as well that many of the marginalised themselves "often believe that powerholders are disinterested in their concerns or that they will face additional problems if they are part of a group that challenges the status quo" (Kirk, 2017, p. 15). EVA-BHN adopted two strategies to overcome these challenges: (1) 'it is unafraid to acknowledge these groups' marginalisation, instead reframing them as potentially powerful social blocks for change. (2) it is sensitive to cultural norms that cannot be overcome within the project's lifespan" (Kirk, 2017, p. 15; Palladium, 2016, pp. 9-10). The inclusion of community members with "the legitimacy to introduce the poor and marginalised to the project's aims" is critical to this approach. E.g. in response to a lack of women in EVA-BHN's community groups a recruitment drive was instigated in the project's second year leveraging existing members' kinship networks and resulting in a significant increase in women's participation. In KP, a well-known Madrassa teacher has been engaged as a recruiter for the project; he encourages potential participants to view its activities in the context of Islam's instructions to raise your voice for the collective good. Hence, EVA-BHN draws on the skills and networks already present in the communities, as well as empowering citizens. It also seeks ways to work with the grain of Pakistan's power and politics, working at different levels of governance (Palladium, 2016, p. 12). EVA-BHN uses an adaptive, politically smart, and locally led approach, key elements include (Kirk, 2017, p. 26):

- Mainstreaming regular Political Economy Analyses: i.e. involving local participants in its analyses.

- Thickening not scaling up: EVA believes that it is more important to build its presence within the localities it works, taking the time to understand its context, than it is to scale up.

- Flexible budgeting is key to adaptability: Flexible budgeting allows it to respond to the fluid political landscape and emerging lessons from the field. 


\section{Other country lessons}

\section{CREID - Participatory action research methodologies for engaging with religious minorities in India}

In a recent CREID working paper, Bharadwaj, Howard and Narayanan (2021) discuss the use of participatory action research (PAR) methodologies for engaging and researching with religious minorities in contexts of intersecting inequalities. PAR methodologies "enable insights into lived experiences of intersecting inequalities" (Bharadwaj, Howard \& Narayanan, 2021, p. 2). There is a focus on India and marginalised groups, such as Denotified Tribes (DNTs), and the intersection of religious belief with caste, tribal, gender etc, as well as poverty. Taking a PAR approach to working with these communities can offer space for reflection, analysis, and sometimes action. "Creating space for highly marginalised groups to engage in policy processes requires redefining expertise and who counts as an 'expert'" (Narayanan, Bharadwaj \& Chandrasekharan, 2015 cited in Bharadwaj, Howard \& Narayanan, 2021, p. 22). The PAR methodologies used include Ground-Level Panels (GLP), community fellows, and community-led action research. "GLPs, in particular, create the scope for people from the margins to share their untold stories, to discuss, dialogue, and analyse, and for their knowledge to be communicated and given weight in policy spaces" (Bharadwaj, Howard \& Narayanan, 2021, p. 34 - see reference for more detailed info on GLPs). Bharadwaj, Howard and Narayanan (2021, p. 15) argue that using PAR approaches are relevant for engaging and researching intersecting inequalities (including FoRB) as they

offer iterative processes which move between first (personal), second (group-based), and third person (between the group and a wider audience/other stakeholders) reflection and dialogue. The methods that are integrated into a PAR process enable participants to bring their embodied and experiential knowledge into the group.... These [different] experiences are held by the group in the safe space of the PAR exercise, where ground rules are set and practices are modelled which ensure respect for diversity (e.g. of gender, age, sexuality, religion, ethnicity, disability) (Bharadwaj, Howard \& Narayanan, 2021, p. 15).

The paper's final section reflects on what was learnt through using PAR methodologies, drawing out these key insights that may be useful:

- Methods for working with vulnerable groups: Methodological innovation is particularly important for working with marginalised and persecuted groups. Bharadwaj, Howard and Narayanan (2021) used PAR to ensure that marginalised voices within marginalised communities are given the space to share and analyse their experiences. The research has demonstrated the value of using PAR methods "which start from people's everyday life experiences, in order to surface and understand the complex realities of how they navigate multiple and intersecting inequalities [and] provide members of these marginalised groups with the tools, skills, and confidence to research their own realities and bring their knowledge into policy spaces" (Bharadwaj, Howard \& Narayanan, 2021, p. 34). Methods need to build confidence and trust; generate data; build capacities; and constantly revisit the links between research and action so that community researchers can assess risk and identify actions. "The experience of the GLP and other participatory processes has highlighted the need to co-create guiding principles for the research 
process, between facilitating organisations and participants, and guided by the context" (Bharadwaj, Howard \& Narayanan, 2021, p. 35).

- Learning about the intersection of religious with other inequalities: PAR processes with DNT groups in India have generated three key areas of learning: nuancing understanding of how religion-based inequalities intersect with others (exclusions are entangled as well as mutually reinforcing. The sense of shared experience and values from religious identities creates collective identity and potential for collective action, yet other identities such as caste can create tensions or other exclusions); challenging assumptions about how people respond and manoeuvre to address multiple exclusions; revealed blind spots that perpetuate these inequalities. "Blind spots relating to the intersection of different stigmatised identities [i.e. intersecting inequalities] are likely to be amplified in development programming and government policies, even while they claim to reduce poverty and promote inclusion in the framework of the SDGs" (Bharadwaj, Howard \& Narayanan, 2021, p. 37).

Bharadwaj, Howard and Narayanan (2021) argue that paying attention to these can help inform and improve programmes and policies to combat exclusions experienced by religious minorities.

\section{Gender and Politics in Practice Research Project - the Waria of Banjarmasin, Indonesia}

The Gender and Politics in Practice research project explored how a gendered understanding of power and politics can make development work more effective using a series of integrated approach case studies. An in-depth case study by Koenig et al. (2018) examined how gender and politics came together in Program Peduli ${ }^{7}$ on transgender empowerment and social inclusion in Indonesia. The program increased "social integration and acceptance for waria ${ }^{8}$ by promoting positive interaction at the household and community levels and with influential individuals" (Koenig et al., 2018, p. 5). It built networks and coalitions of local social change actors using political analysis, and also lobbied government authorities to formally register Banjarmasin's waria association and improve social services for waria. Some of the key design elements included:

- The program "employed waria in key roles and involved local waria leaders from the outset in guiding and implementing the work" prioritising local networks and knowledge (Koenig et al., 2018, p. 5). In the building and make-up of the national project teams a clear emphasis was put on local ownership and legitimacy, furthermore the hiring of waria (even though they were less experienced) "also helped overcome initial concerns about an overly rigid approach to designing and implementing programs" (Koenig et al., 2018 , p. 17). This enabled a high level of trust among programme stakeholders.

\footnotetext{
"Program Peduli operat[ed] across Indonesia, implemented by the Asia Foundation with support from DFAT and the Indonesian government. It seeks social inclusion among six of Indonesia's marginalised groups - one of which is waria - by looking for ways to change the social relations that govern access to resources and economic opportunities" (Koenig et al., 2018, p. 5).

8 "Waria is a person who is genetically male, but identifies and expresses (e.g. behaves and dresses) as a woman" (Dede Oetomo (1996), Gender and Sexual Orientation in Indonesia cited in Koenig et al., 2018, p. 8).
} 
- A large array of local change agents were involved, especially in strategic decisionmaking, and the programme "connected to and supported existing movements and networks rather than trying to convene a new one" (Koenig et al., 2018, p. 17). However, it was noted that "even within the waria community there are differing ideas about how best to improve lives in their community" - demonstrating that marginalised groupings themselves (such as religious minorities, transgender people, persons with disabilities) are not homogenous but complex and multifaceted, with differing opinions. This meant that "despite extensive local consultation with waria, the program still had to make thoughtful choices on strategy as options enjoyed consensus support within the waria community" (Koenig et al., 2018, p. 18).

- The gendered elements of politics and power dynamics were considered from the outset; "the team's understanding of the central role that waria's gender plays in their social exclusion informed project goals, strategies and activities" (Koenig et al., 2018, p. 5).

- A flexible participatory approach was supported through the use of simplified tools (e.g. gender analysis and stakeholder maps), mentoring and peer learning events, coalition building and adaptation (including in shifting its strategy over time - e.g. moving its networking away from government actors towards influential community members).

- "The project was politically informed, but less 'politically active'" - instead, choosing to pursue changing "hearts and minds to increase social acceptance" rather than policy reform (Koenig et al., 2018, p. 5). This was informed by its political analysis, where legitimate fear of backlash was a key factor raised. 


\section{References}

Bharadwaj, S.; Howard, J. and Narayanan, P. (2020) Using Participatory Action Research Methodologies for Engaging and Researching with Religious Minorities in Contexts of Intersecting Inequalities, CREID Working Paper 5, Coalition for Religious Equality and Inclusive Development, Brighton: Institute of Development Studies. DOI: 10.19088/CREID.2020.009 https://opendocs.ids.ac.uk/opendocs/handle/20.500.12413/15896

Carter B., Joshi, A., \& Remme, M. (2018). Scaling up inclusive approaches for marginalised and vulnerable people. K4D Emerging Issues Report. Brighton, UK: Institute of Development Studies. https://opendocs.ids.ac.uk/opendocs/handle/20.500.12413/13964

Jewkes, R. (2019). What works to prevent violence against women and girls? Lessons from DFID's flagship programme. PowerPoint Presentation. What Works. https://www.whatworks.co.za/documents/publications/336-4-what-works-jewkes-wiltonpark-may-2019-v2/file

Jewkes, R., Willan, S., Heise, L., Washington, L., Shai, N., Kerr-Wilson, A, Christofides, N. (2020a). Effective design and implementation elements in interventions to prevent violence against women and girls: Evidence Brief. What Works To Prevent VAWG? Global Programme Synthesis Product Series. Pretoria: South African Medical Research Council. https://www.whatworks.co.za/documents/publications/377-effective-design-andimplementation-briefweb25-02-20/file

Jewkes, R., Willan, S., Heise, L., Washington, L., Shai, N., Kerr-Wilson, A, Christofides, N. (2020b). Effective design and implementation elements in interventions to prevent violence against women and girls. What Works To Prevent VAWG? Global Programme Synthesis Product Series. Pretoria: South African Medical Research Council. https://whatworks.co.za/documents/publications/373-intervention-report19-02-20/file

Kerr-Wilson, A.; Gibbs, A.; McAslan Fraser E.; Ramsoomar, L.; Parke, A.; Khuwaja, HMA.; \& Jewkes, R. (2020). A rigorous global evidence review of interventions to prevent violence against women and girls, What Works to prevent violence among women and girls global Programme, Pretoria, South Africa. https://www.whatworks.co.za/documents/publications /374-evidence-reviewfweb/file

Khan, A. and Qidwai, K. (2021) Donor Action in Pakistan: A Comparative Case Study of CDIP and AAWAZ, IDS Working Paper 549, Brighton: Institute of Development Studies, DOI:10.19088/IDS.2021.025

Khattak, R. \& Higdon, G. (2020). Strengthening Women's Political Participation in Pakistan, Oxfam's Inspiring Better Futures Case Study Series, Oxford: Oxfam International. https://oxfamilibrary.openrepository.com/handle/10546/621107

Kirk, T. (2017). A strategic approach to social accountability in Pakistan. Brighton, UK: Institute of Development Studies.

https://opendocs.ids.ac.uk/opendocs/bitstream/handle/123456789/13275/Wp497\%20Onli ne.pdf? sequence $=1$ \&isAllowed $=y$

Koenig, M., Rahman, E., Lau, B., Dewa, B.E.C. \& Ladner, D. (2018). Thinking and Working Politically for Social Inclusion: The Waria of Banjarmasin, Indonesia, Gender and Politics 
in Practice Research Project, DLP \& The Asia Foundation.

https://www.dlprog.org/publications/research-papers/thinking-and-working-politically-forsocial-inclusion-the-waria-of-banjarmasin-indonesia

Lind, A. (2010). 'Introduction: Development, Global Governance, and Sexual Subjectivities', in A. Lind (ed.), Development, Sexual Rights and Global Governance. New York: Routledge: 1-20. https://www.taylorfrancis.com/books/oaedit/10.4324/9780203868348/development-sexual-rights-global-governance-amy-lind

Maheshwary, S. (2020) Experiences of Intersecting Inequalities for Poor Hindu Women in Pakistan, CREID Policy Briefing 2, Coalition for Religious Equality and Inclusive Development, Brighton: IDS. DOI: 10.19088/CREID.2020.012 https://opendocs.ids.ac.uk/opendocs/handle/20.500.12413/15879

Palladium (2016). Reframing citizen-state relations from the bottom-up. EVA-BHN's model of social accountability in Pakistan. London: Palladium. https://drive.google.com/file/d/0B4c6dFNI7aQITVhWMWF6WFpzOTQ/view

Suleman, N. (2020) Experiences of Intersecting Inequalities for Christian Women and Girls in Pakistan, Policy Briefing 3, Coalition for Religious Equality and Inclusive Development, Brighton: Institute of Development Studies. DOI: 10.19088/CREID.2020.013

Sultan, S.; Kanwer, M. and Mirza, J. (2020) A Multi-layered Minority: Hazara Shia Women in Pakistan, Policy Briefing 1, Coalition for Religious Equality and Inclusive Development, Brighton: Institute of Development Studies. DOI: 10.19088/CREID.2020.011

Tadros, M. (2020a) Promoting FoRB in Fragile Contexts: Emerging Lessons from CREID, Learning Brief, Coalition for Religious Equality and Inclusive Development, Brighton: IDS. https://opendocs.ids.ac.uk/opendocs/handle/20.500.12413/15277

Tadros, M. (2020b) Violence and Discrimination against Women of Religious Minority Backgrounds in Pakistan, CREID Intersections Series, Coalition for Religious Equality and Inclusive Development, Brighton: IDS. DOI: 10.19088/CREID.2020.003 https://opendocs.ids.ac.uk/opendocs/handle/20.500.12413/15800

UNDP. (2010). Marginalised Minorities in Development Programming: A Resource Guide and Toolkit. UNDP. https://www.undp.org/content/undp/en/home/librarypage/democraticgovernance/human_rights/marginalised-minorities-in-development-programming-aresource-guide-and-toolkit.html

\section{Key websites}

- CREID: https://www.ids.ac.uk/programme-and-centre/creid/

- What Works to Prevent Violence: https://whatworks.co.za/ 


\section{Acknowledgements}

We thank the following experts who voluntarily provided suggestions for relevant literature or other advice to the author to support the preparation of this report. The content of the report does not necessarily reflect the opinions of any of the experts consulted.

- Kathryn Cheeseman, IDS

- Mariz Tadros, IDS

\section{Suggested citation}

Price, R.A. (2021). Inclusion of marginalised groups in sensitive programming in Pakistan. K4D Helpdesk Report 996. Brighton, UK: Institute of Development Studies. DOI: 10.19088/K4D.2021.090

\section{About this report}

This report is based on six days of desk-based research. The K4D research helpdesk provides rapid syntheses of a selection of recent relevant literature and international expert thinking in response to specific questions relating to international development. For any enquiries, contact helpdesk@k4d.info.

K4D services are provided by a consortium of leading organisations working in international development, led by the Institute of Development Studies (IDS), with the Education Development Trust, Itad, University of Leeds Nuffield Centre for International Health and Development, Liverpool School of Tropical Medicine (LSTM), University of Birmingham International Development Department (IDD) and the University of Manchester Humanitarian and Conflict Response Institute (HCRI).

This report was prepared for the UK Government's Foreign, Commonwealth \& Development Office (FCDO) and its partners in support of pro-poor programmes. Except where otherwise stated, it is licensed for non-commercial purposes under the terms of the Open Government Licence v3.0. K4D cannot be held responsible for errors or any consequences arising from the use of information contained in this report. Any views and opinions expressed do not necessarily reflect those of FCDO, K4D or any other contributing organisation.

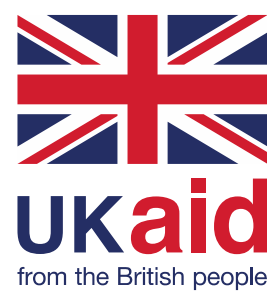

(C) Crown copyright 2021. 